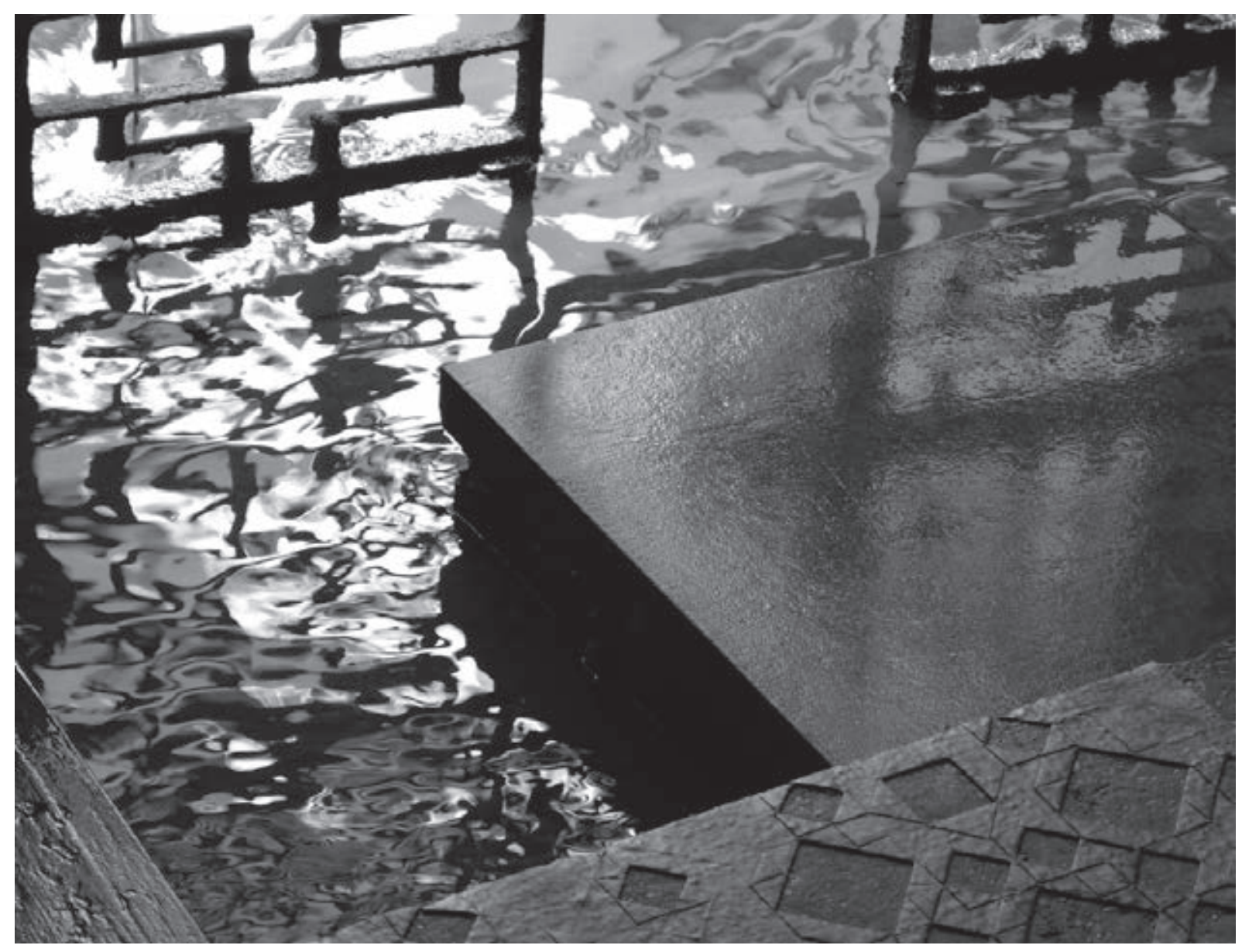




\section{¿De qué substancia está hecha la arquitectura? Contigüidades y serendipias en torno al agua en el proyecto contemporáneo Juan Domingo Santos Carmen Moreno Álvarez}

El texto versa sobre el reencuentro de la creación con la contigüidad universal de pensamiento, materia y forma, y cómo ciertas arquitecturas son concebidas de una substancia única que se transfiere a los elementos que integran la obra. El artículo pone en crisis la condición estrictamente técnica de gran parte de la arquitectura del siglo XX -especialmente del Movimiento Moderno-, con un "ensimismamiento" de la disciplina vista desde la técnica y el repertorio de materiales. Aunque no es posible generalizar y los caminos del proyecto contemporáneo son amplios, se podría hablar de una cierta línea de pensamiento heredera de una contigüidad universal (Ovidio, Fourier, Calvino) presente en ciertas arquitecturas de la historia que establecen una clara diferenciación entre los materiales de construcción y la substancia con la que se concibe la arquitectura. El texto es una reflexión sobre estas cuestiones tomando el agua como argumento para la creación en la arquitectónica.

\section{PALABRAS CLAVE}

Contigüidad, agua, supramaterias, substancia

KEYWORDS

Contiguity, Water, Supramaterials, Substance
CONTIGÜIDADY SUPRAMATERIAS

En 1985, el año anterior a su fallecimiento, el artista Joseph Beuys realizó la obra Lemon Light (Capri-Battery)' (fig. 02). En una primera aproximación, la instalación es una metáfora moderna sobre el balance ecológico y el equilibrio que deben mantener los objetos producidos por el hombre con la naturaleza, y hasta qué punto los cambios operados por esta última pueden condicionar la creación humana. Pero más allá de esta dimensión ecológica y medioambiental, la instalación plantea de
Juan Domingo Santos

(Granada, 1961). Catedrático de Proyectos Arquitectónicos. Departamento de Expresión Gráfica Arquitectónica y en la Ingeniería (Director del Departamento). Escuela Técnica Superior de Arquitectura. Universidad de Granada. Email: jdomingosantos@gmail.com. Arquitecto y profesor en la ETSA de Granada desde 1993. Ha publicado en revistas como El Croquis, Arquitectura Viva, Tectónica, A+t, Casabella, AR Architectural Review, Bauwelt, GA Document, Y Área, entre otras; y en libros de arquitectura editados por Taschen, Gustavo Gili, Fundación Arquia y Electa. Su obra ha sido seleccionada en exposiciones como On Site (MoMA) Nueva York, XI y III Bienal Española de Arquitectura y Urbanismo (BEAU), y en las ediciones $15^{\mathrm{a}}$ y $7^{\mathrm{a}}$ Biennale di Architettura di Venezia. Nominado a los Premios Mies van der Rohe (2007), premio Enor (2011), reconocimiento de Arquitectura XI BEAU, y premio en la VIII BIAU. Su obra "Maqueta. Casa en un huerto de cerezos" forma parte de la Colección permanente de Arquitectura y Diseño del MoMA de Nueva York (2006). Ha sido Co-Director de la XIII BEAU (2015-2017). Su libro "La tradición innovada. Escritos sobre regresión y modernidad" ha ganado el premio FAD de Pensamiento y Crítica 2014. E-Mail: jdomingosantos@gmail.com Orcid ID 0000-0002-7504-591

Fig. 01

Fundación Querini Stampalia, Venecia (Italia), 1961-1963. Arquitecto: Carlo Scarpa. Imagen de la cancela de entrada con el acqua alta. 


\section{Carmen Moreno Álvarez}

(Granada, 1976). Profesora Ayudante Doctora. Área de Proyectos

Arquitectónicos. Departamento de Expresión Gráfica Arquitectónica y en la Ingeniería. Escuela Técnica Superior de Arquitectura. Universidad de Granada. Email: carmenmorenoalvarez@gmail.com. Profesora de Proyectos Arquitectónicos de la ETSA Granada desde 2007. Sus trabajos y artículos han sido publicados en revistas como AV Monografías, Arquitectura Viva, Pasajes, Arquitectos, Neutra, Revista del CSCAE, La Vanguardia, Arkitecten; y en libros editados por Fundación Arquia, On Diseño, Pencil, Links, dda Detalles de Arquitectura, entre otros. Ha participado en exposiciones internacionales como la XIV Bienal Española de Arquitectura y Urbanismo 2018; $17^{\mathrm{a}}, 15^{\mathrm{a}}$ y $9^{\mathrm{a}}$ Biennale di Architettura di Venezia 2020, 2016 y 2008, Muestra Internacional de Patrimonio Arquitectónico Beijign 2014 o la exposición de Jóvenes Arquitectos Españoles del Ministerio de la Vivienda en 2007. Premios destacados: Premio de Paisaje y Premio Transversal COA de Granada 2019, Finalista XIV BEAU, Premio Emporia 2016, Finalista y Seleccionada Premios FAD 2007,2019 y 2020 . Ha sido Co-Directora de la XIII BEAU (2015-2017). Es miembro la Unidad de Excelencia "Ciencia en la Alhambra" y del Grupo de Investigación HUM-813 "Arquitectura y Cultura Contemporánea".

E-Mail: carmenmoreno@ugr.es Orcid 0000-0002-3764-1464

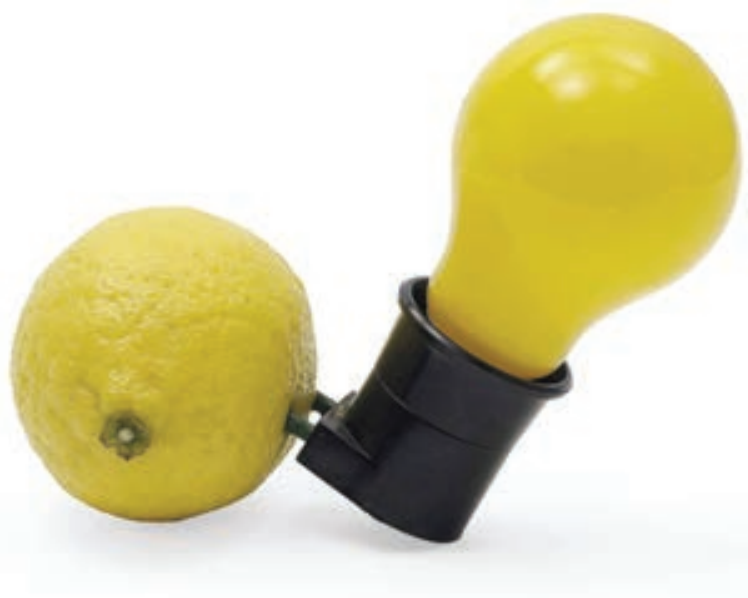

fondo el reencuentro de la creación con la contigüidad universal de pensamiento, materia y forma, una cuestión que preocupó al artista a lo largo de su vida y que convertiría en el argumento principal de sus trabajos y creaciones. La obra muestra cómo cualidades de una materia pueden transferirse a otras, otorgándole al conjunto de elementos que la integran un cuerpo formado por una substancia única. Más allá de la apariencia, la significación de la obra es amplia, y se encuentra dentro de las acciones plásticas (Aktionen) llevadas a cabo por el artista movido por el interés en el cambio de estado de los cuerpos y la transferencia energética del pensamiento a la materia. Obras como Silla con grasa (1960), Bomba de miel en el lugar de trabajo (1974-1977), Voglio vedere le mie montagne (1971) o 7000 robles (1982), inciden en la energía que fluye entre cuerpos diferentes vistos como una substancia única que envuelve a objetos e ideas por encima de su propia realidad física, e informan simbólicamente de la energía acumulada en la materia².

Los arquitectos Herzog y De Meuron, colaboradores de Joseph Beuys en algunas acciones plásticas llevadas a cabo por el artista, realizaron en 1984 una ampliación de una casa en un jardín, vinculando la actuación a una pauwlonia adulta (fig. 03). La construcción está influida por las ideas de contigüidad planteadas por Beuys en la instalación 7000 robles realizada con motivo de la VII Documenta de Kassel dos años antes. EI resultado de la ampliación es un tándem árbol-arquitectura que comparte una energía participativa común que los implica mutuamente. La inflexión del pabellón, los movimientos de circulación en el interior del espacio y la utilización de la madera contrachapada para la construcción, muestran una serie de decisiones motivadas por la presencia y la energía irradiada por el árbol, que determinan que ambos objetos de naturaleza diferente estén "enraizados", condicionando el crecimiento futuro de la pauwlonia y la vida del pabellón y su arquitectura a partir de ese momento.

Años antes de la creación de Lemon-Light, el escritor Italo Calvino había planteado ya en su ensayo Ovidio y la contigüidad universal (1979) ${ }^{3}$ el argumento de la contigüidad de todas las figuras o formas de lo existente (firmamento, dioses, reino animal o mineral, flora y seres humanos), estableciendo una línea de aproximación entre el mundo de 
la mitología -los dioses-, y el mundo terrenal de los seres humanos y la naturaleza. En su escrito, Calvino sitúa el mundo terrenal del que habla Ovidio en "un universo donde las formas llenan el espacio intercambiando mutuamente sus cualidades y dimensiones (....), unas y otras se entrelazan en una sola espiral"4, compartiendo una misma substancia. La idea de situar la acción en un escenario de "límites indistintos entre mundos diferentes", como plantea el texto, implicaba superar la distancia que separa estos dos estados de naturaleza antagónica. Mediante la contigüidad, la mitología y la realidad cotidiana podrían transmutarse formando parte de un mismo cuerpo, reencontrando parentescos y semejanzas a través de piedras y otras materias terrenales que toman vida convertidas en seres mitológicos ${ }^{5}$.

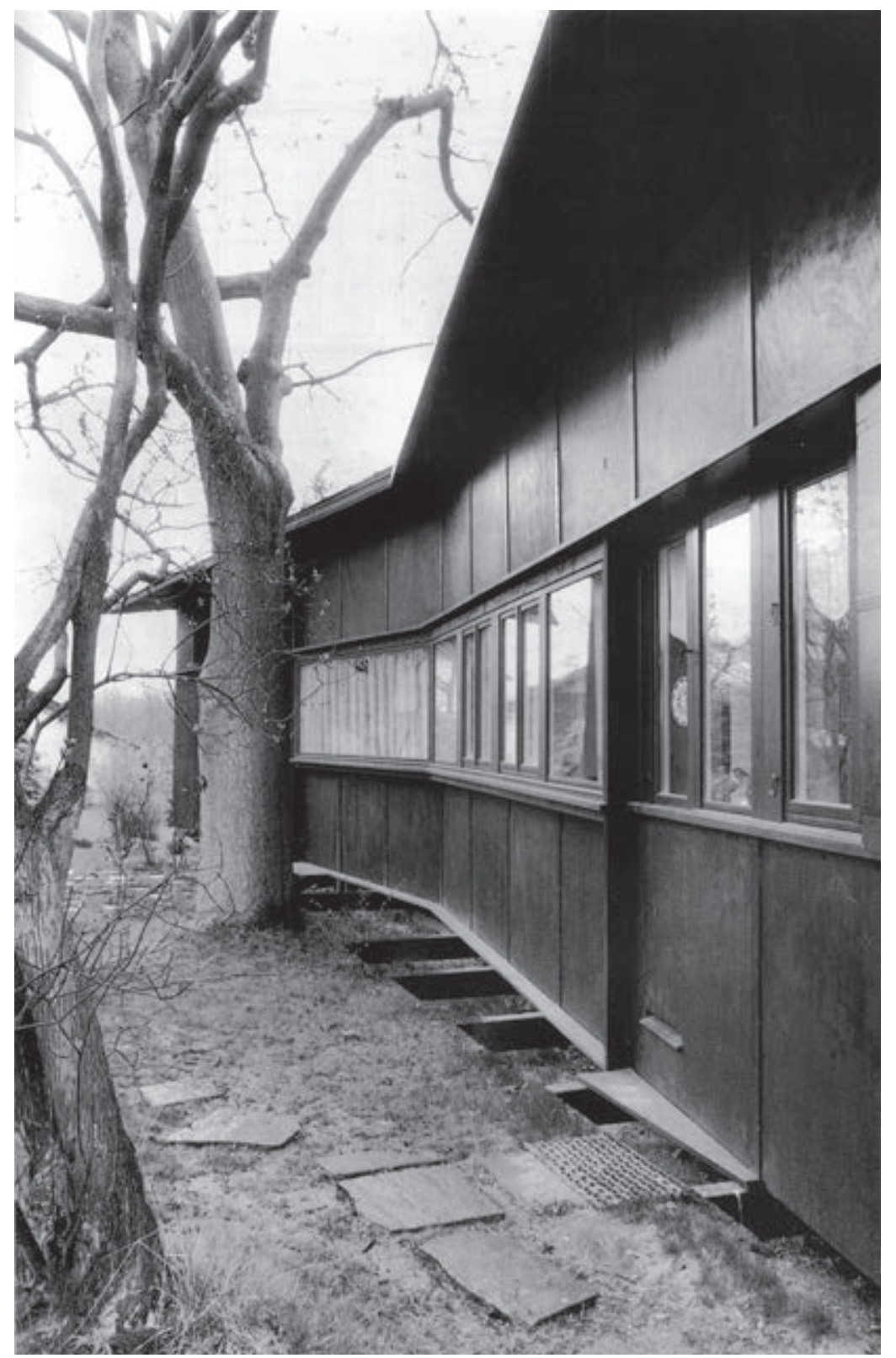

Fig. $\mathrm{O} 2$

Joseph Beuys, Lemon Light (CapriBattery), 1985. (Fuente: https://www. christies.com/lotfinder/Lot/josephbeuys-1921-1986-capri-batterie5780657-details.aspx. Fecha de consulta: 3/04/2020).

Fig. 03

Plywood House, Bottmingen (Suiza), 1984-1985. Arquitectos: Herzog \& de Meuron. (Fuente: Revista El Croquis, 2000, n. 60+84). 


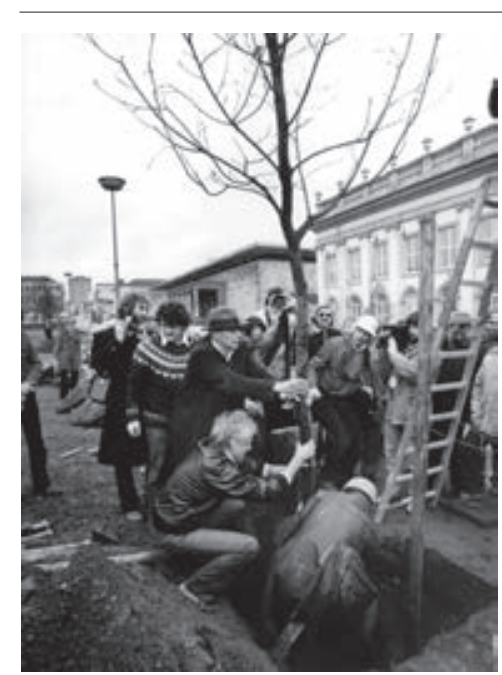

Fig. 04

Joseph Beuys, 7000 robles, Kassel (Alemania), 1982. La imagen muestra al artista plantando el primer árbol junto a la piedra de basalto acompañado por un grupo de ciudadanos. (Fuente: 7000 EICHEN. Joseph Beuys. CD-ROM. Fundación 7000 robles y Ministerio para la Ciencia y el Arte, Kassel).
Tanto Beuys como Calvino, dos figuras coetáneas e influyentes en sus respectivos campos, recurrieron en la segunda mitad del siglo $X X$ a la contigüidad universal de materia, conceptos y formas para desarrollar sus creaciones. En el caso de Beuys, los planteamientos de contigüidad son prolongación de las experiencias vitales del artista, y sus Aktionen, flujos que conectan pasado, presente y futuro para sobrevivir al trauma de la guerra que le acompañó en vida y que el artista plasmó en sus trabajos empleando materiales poco estables que representan estados de transformación en evolución permanente ${ }^{6}$. Para Calvino se trataba de la construcción intelectual de un cuerpo literario concebido a través de un flujo de estados transitorios y continuos que, indistintamente y de manera libre, se mueven entre realidades distintas. De alguna manera ambos creadores abogaron con sus trabajos por una dimensión que trasciende la materialidad, fundamentando sus ideas y realizaciones en la transubstanciación de la obra y en la energía natural que le fue dada a la humanidad por encima de su realidad física, una substancia única y simbólica que relaciona el pensamiento, la materia y la forma mediante la contigüidad de los elementos que componen la obra.

Los artistas de las vanguardias europeas de la segunda mitad del siglo XX, recuperaron tras la Segunda Guerra Mundial el interés por la descomposición de la materia orgánica en general y las transmutaciones del cuerpo humano, una idea que se extendería a otros elementos físicos de la naturaleza. Materiales de desecho reciclados, que continuaban su deterioro tras la finalización de la obra, se hicieron presentes en sus trabajos en un proceso evolutivo y de transformación. Tapies y Saura en España, Dubuffet en Francia, Bacon en Inglaterra, Kounellis en Grecia, Auerbach y Beuys en Alemania, entre otros, abordaron la degradación y disolución de la materia, mostrando un interés especial hacia cuestiones que vinculaban pensamiento, energía y transformación, a partir de una materia que se convierte en substancia primordial que se transfiere tomando cuerpo de distintas maneras $y$ formas ${ }^{7}$. Más tarde, entrado el siglo XXI, el arte extendería estas cuestiones a un cuerpo de orden superior, más interesado en cuestiones de tipo social que incluían procesos colaborativos en contextos sociales, culturales y políticos, incorporando a las personas, e incluso a la ciudad y su entorno, a través de proyectos con una fuerte condición cívica como substancia motriz de la intervención. La condición mítica y simbólica que movía a un pueblo a realizar las construcciones históricas del pasado sería reemplazada por una dimensión simbólica terrenal de seres humanos y conflictos sociales. Obras como Cuando la fe mueve montañas de Francis Alÿs, una instalación realizada en Lima en abril de 2002, que congregó quinientos voluntarios para desplazar diez centímetros de su posición una duna de arena de quinientos metros de diámetro con la utilización de una simple pala ${ }^{8}$, o las prácticas colaborativas de Beuys en su obra 7000 robles. Embosquecer la ciudad frente a administrar la ciudad (1982), una instalación que congregó a los ciudadanos de Kassel consistente en la plantación de 7000 robles junto a otras tantas piedras de basalto en distintos espacios públicos de la ciudad', son exploraciones colectivas sobre la comunicación y la cooperación social que podría trasladarse a otros lugares. Tienen el poder de congregar en torno a ellas y bajo una substancia común, cuestiones muy diversas con una componente utópica de concienciación que muestran "lo que fuimos capaces de hacer juntos" (fig. 04). 
Más allá de la argumentación literaria de Calvino y de las experiencias artísticas de Beuys y de otros artistas contemporáneos sobre la contigüidad de la materia, en el libro Argumentos. Sobre la contigüidad en la arquitectura (2001) ${ }^{10}$, el arquitecto Juan Luis Trillo recoge una serie de reflexiones sobre las supramaterias como argumento para la creación y la actividad de transubstanciar empleada en los procesos creativos del arte y de la ciencia, situando estos procesos en los espacios de intersección y en los límites entre mundos diferentes como lugares energéticos para la creación. En el libro se trasladan estas cuestiones a la arquitectura, entendida como una "acción intersectiva" del proyecto arquitectónico que rige la concepción de la obra por encima de la consideración pragmática de la construcción. La contigüidad está tratada en sus páginas como una "cremallera" que enlaza las cosas más variopintas, acciones energéticas que permiten convertir pensamientos, objetos, situaciones, memorias o recuerdos, en formas materiales concebidas bajo una substancia común. Conceptos como transferencia, contaminación, metamorfosis o transusbstanciación (en la línea propuesta por Beuys y Calvino), son utilizados para superar los límites que impone la disciplina autónoma de la arquitectura y su construcción, recurriendo a la capacidad del proyecto arquitectónico para imaginar tramas o argumentos en los "límites que separan mundos distintos", con relaciones que amplían el significado y dotan de una dimensión vital y simbólica a la arquitectura.

AGUA Y PIEDRA. SUBSTANCIAS DE LA ARQUITECTURA
La contigüidad universal ha sido propia de ciertos momentos de codificación artística a lo largo de la historia de la arquitectura, que han asumido la conversión en símbolos de una serie de experiencias que superan, a través de la abstracción intelectual, el simple pragmatismo

de la construcción. Las substancias presocráticas como el aire, el fuego, la luz, el agua, incluso la piedra o la tierra, a las que podrían añadirse fenómenos como la humedad, la temperatura o el sonido, constituyen un conjunto de elementos y acciones que podríamos definir como no-materiales, $y$ forman parte de un pensamiento esencial que envuelve a la arquitectura con una dimensión energética capaz de conciliar y aglutinar la consideración constructiva de la obra en torno a ellas. Algunas arquitecturas de la historia concebidas a partir de una substancia única, como el Panteón romano de Agripa y la relación matemática que establece la luz con la geometría, la Acrópolis de Atenas levantada con la piedra tallada de la colina sobre la que se asienta y en continuidad con ella, la ciudadela inca de Machu Pichu, un complejo sistema hidrológico, urbano y agrícola construido en terrazas de piedra seca en el macizo montañoso de los Andes a 2.400 metros de altura según las alineaciones astronómicas y rindiendo culto a las montañas -los dioses- que la rodean, y la Alhambra de Granada en torno al agua y a una idea de representación del jardín del paraíso en la tierra, son portadoras de una energía original sublime desencadenante del proyecto arquitectónico por encima de cuestiones de programa o de la simple materialidad constructiva. Luz, piedra y agua para concebir una serie de arquitecturas fundamentadas en la experimentación con una supramateria que las dota de significación y de dimensión simbólica. La condición casi inmaterial de estas materias básicas, especialmente el agua y la luz, que ni envejecen ni tienen memoria, están en continuo fluir y no poseen una estabilidad 


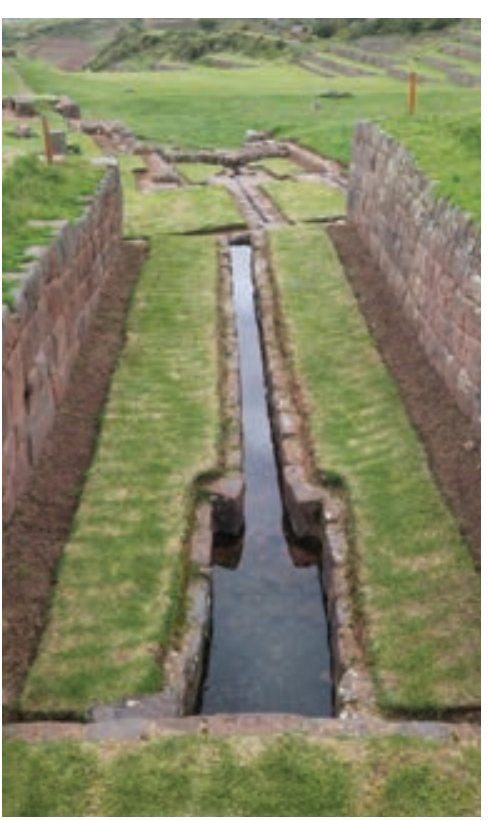

05 formal ni material -a diferencia de la piedra-, tienen la capacidad de erosionar y transformar los objetos dejando su huella al pasar por ellos, ampliando su condición material con nuevas relaciones y formas, convertidos en "puro contenido" por efecto de una substancia mayor.

Algunas arquitecturas históricas han recurrido al agua como substancia creativa y representación de un paisaje que va más allá de lo terrenal, es el caso del conjunto palaciego, religioso y ceremonial de Tipón en la cultura incaica cerca de Cuzco, un admirable sistema de conducción y distribución de agua para la irrigación agrícola en convivencia con las construcciones religiosas y la casa real entre bellos jardines en terrazas de piedra (fig. 05), o la Alhambra de Granada de época islámica, un palacio de agua entre patios, jardines y murallas como metáfora del paraíso. Todos ellos, complejos arquitectónicos que trascienden los usos de la vida diaria convertidos en lugares de culto al agua. En estas arquitecturas, el agua es la substancia que modela el paisaje y el espacio a diferentes escalas y con diferentes manifestaciones. En el caso de la Alhambra, su presencia adquiere diversos rostros, puede ser simbólica, metafórica o abstracta, actuar por analogía con ciertas formas y situaciones que evocan el paraíso, al mismo tiempo que regular térmicamente espacios y patios en perfecta sincronía entre lo fenomenológico, lo artístico y lo técnico, además de poseer connotaciones poéticas y emocionales sublimes".

En la Alhambra, la luz y el agua crean diferentes efectos y relaciones con un repertorio iconográfico muy variado. Hay reflexiones especulares, transparencias, disolución y multiplicación de formas, refracción de imágenes, ingravidez y ligereza, ampliando la percepción y el significado de la arquitectura del palacio y del jardín que se extiende más allá de sus límites reales. La evanescencia que provoca el agua en los espacios interiores y patios permite diluir las fronteras entre la realidad y la ficción para construir paisajes oníricos de la imaginación (fig. 06). Los efectos del agua en estos espacios son realmente bellos y sorprendentes,

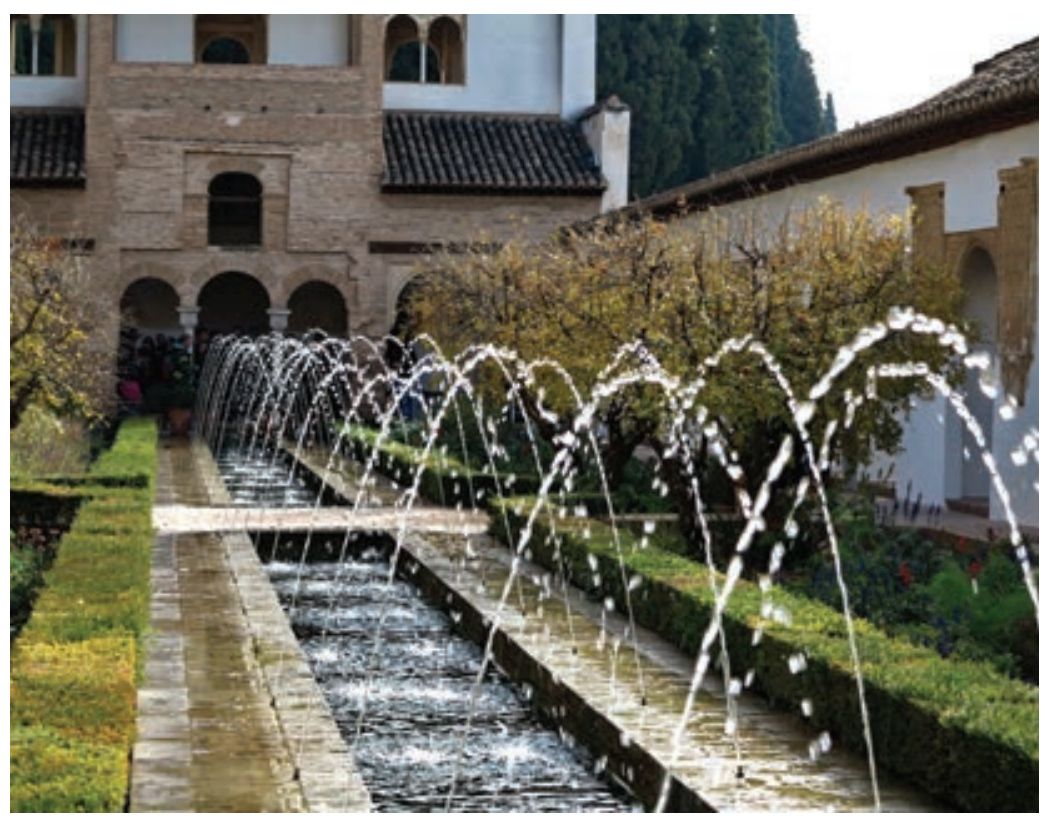


no solo por la apariencia estética que provocan, sino porque ponen en crisis algunas cuestiones de fondo sobre el significado de ciertos conceptos tradicionalmente vinculados entre sí en Occidente, como solidez/opacidad y ligereza/transparencia. Contemplando cómo es utilizada el agua en la Alhambra es posible plantear la disolución de asociaciones convencionales de este tipo con nuevas relaciones que remiten a un mundo de fascinación, donde lo opaco puede llegar a ser ligero y lo sólido transparente $^{12}$. Esta utilización del agua también alcanza en ocasiones una sutil alteración de los elementos plásticos tradicionales al convertirse, junto al mármol blanco, en materia sustancial de la obra de arte como sucede en la fuente de los Leones.

La Alhambra es una experiencia estética concebida de una substancia única que la hace atemporal. Lo verdaderamente especial es su capacidad para atrapar el tiempo en un lugar donde la vida se manifiesta en cada rincón y a cada momento a través de la sorprendente contigüidad entre naturaleza, arquitectura y ornato, como símbolo de una cultura. Resulta difícil olvidar las sensaciones que se experimentan ante estos espacios llenos de vida que preservan la humanidad en la arquitectura.

Este simbolismo presente en la Alhambra y en algunas arquitecturas de referencia de la historia, se redujo en la arquitectura del siglo XX, y especialmente durante el Movimiento Moderno, a un problema estrictamente técnico, y la construcción, a un repertorio de materiales y soluciones tipificadas frente a la arquitectura de otras épocas portadoras de una condición simbólica ${ }^{13}$. Son escasas las arquitecturas de este periodo que han tenido en cuenta las substancias presocráticas para la concepción del proyecto arquitectónico. El agua, al igual que el resto de supra-materias, no fue considerada una substancia para pensar la arquitectura frente a materiales como el hormigón, el acero o la madera, que ensamblaban adecuadamente en el proceso de una lógica constructiva. En las obras de esta época, el agua aparece casi siempre como un cuerpo añadido (una piscina, una alberca o formando parte de un paisaje), o bien está tratada con una visión estrictamente técnica. Son muy pocas las intervenciones que la han incorporado como substancia desencadenante del proyecto arquitectónico, y al mismo tiempo, han sido objeto de relación y transferencia entre los diferentes elementos que integran la obra. Su utilización se ha reducido fundamentalmente a la mera contemplación y a establecer experiencias sensoriales en torno a ella casi siempre en situaciones excepcionales ${ }^{14}$.

Podemos encontrar algunos casos, los menos, en los que el agua se ha convertido en la propia substancia identitaria que da forma a la arquitectura en contigüidad con ella y sus transformaciones, un proceso abierto a la posibilidad de que surja el "milagro" de la transubstanciación de ideas, formas y materias para alcanzar un cuerpo único en la obra, como sucede en el laboratorio del alquimista ${ }^{15}$. Es el caso de la Casa Farnsworth (1950) de Mies van der Rohe, concebida como una máquina para quedar flotando entre árboles en el paisaje con las crecidas de agua del río Fox, de la remodelación de la Fundación Querini Stampalia (1961) de Carlo Scarpa, donde la planta baja y el jardín emergen y se sumergen bajo las aguas, desdibujando su forma con las inundaciones naturales y cambios de nivel de la Laguna de Venecia ${ }^{16}$, o la Casa de la Lluvia (1979) en Cantabria de Juan Navarro Baldeweg, una caja de resonancia que solo es posible percibir en su totalidad con las precipitaciones y las transformaciones que la humedad de la lluvia provoca sobre 


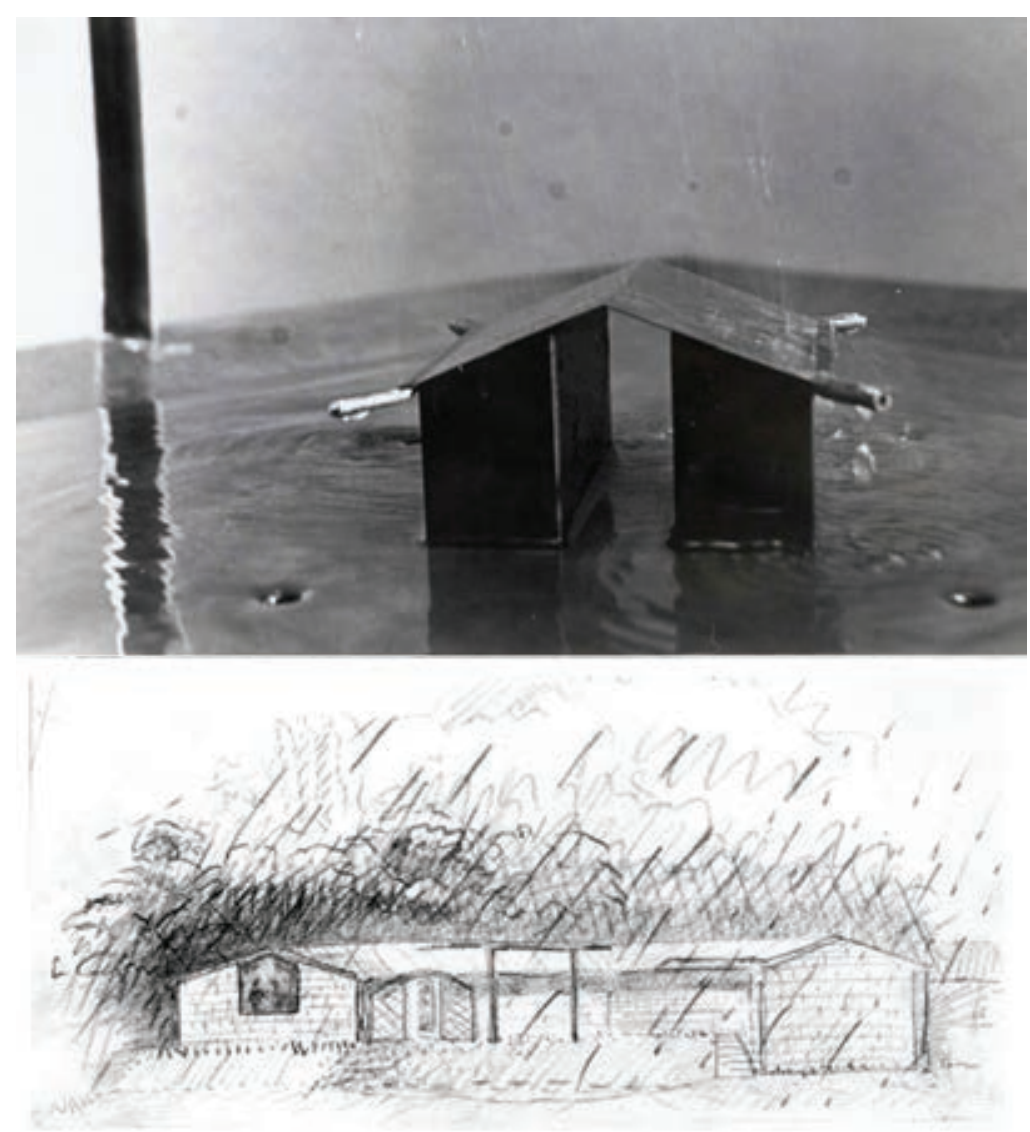

07

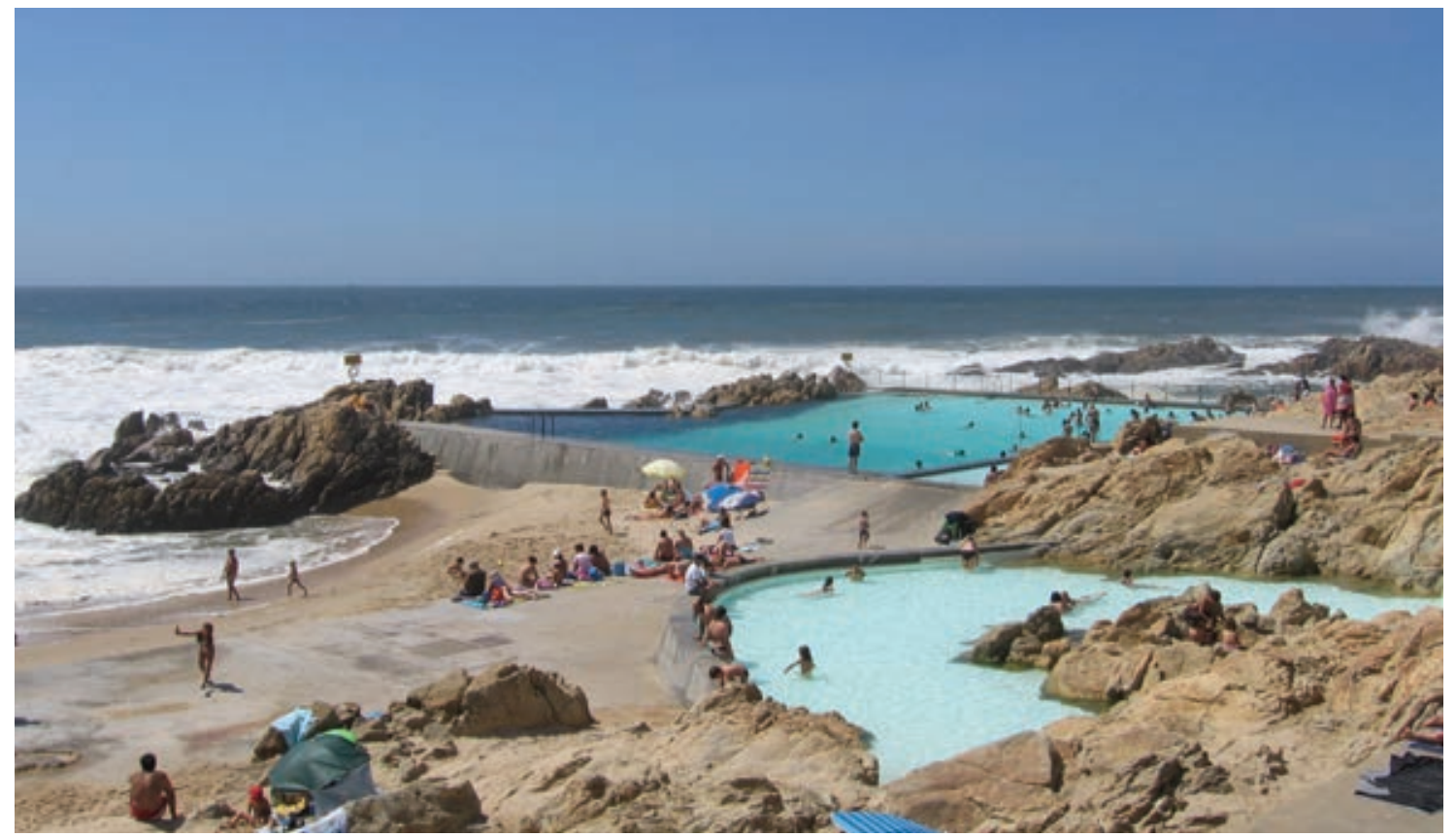


el material y la apariencia de la casa ${ }^{17}$ (fig. 07). Pero, sobre todo, la contigüidad universal entre materia, idea y forma de la que habla Calvino en su ensayo, la encontramos sin duda en las Piscinas Das Marés (1966) de Álvaro Siza, construidas dentro de los límites rocosos de la costa y con el agua del propio océano Atlántico, que como un estanque al que se arroja una palangana repleta del mismo material, diluye su forma en continuidad con el agua del océano sobre el que se extiende. Agua dentro de agua para un proceso proyectual basado en la transubstanciación de una materia única hasta alcanzar la fascinación en un espacio acotado que diluye sus fronteras ${ }^{18}$ (fig. 08). Pocas creaciones como esta abordaron durante el siglo XX una intervención bajo una substancia universal que condujera los designios de la obra en la línea de los paisajes agregados que Joseph Beuys nos mostraría más tarde en su obra Lemon Light y que el crítico Jean Louis Cohen definiría como "hacer de los ambientes la materia (substancia) constructiva de la obra"19.

Continuando con esta línea de pensamiento y de acción, es posible que el interés y vigencia de los paseos que Dimitri Pikionis realizó para conectar la ciudad de Atenas con la subida a la Acrópolis y a la colina de Filipappo (1954-1957), se deba en gran medida a un trabajo abordado desde la contigüidad con la materia de este paisaje, la piedra (fig. 09). La obra es una manifestación culta de la contemporaneidad sobre la contigüidad territorial de tiempo y materia. La trama de pa-

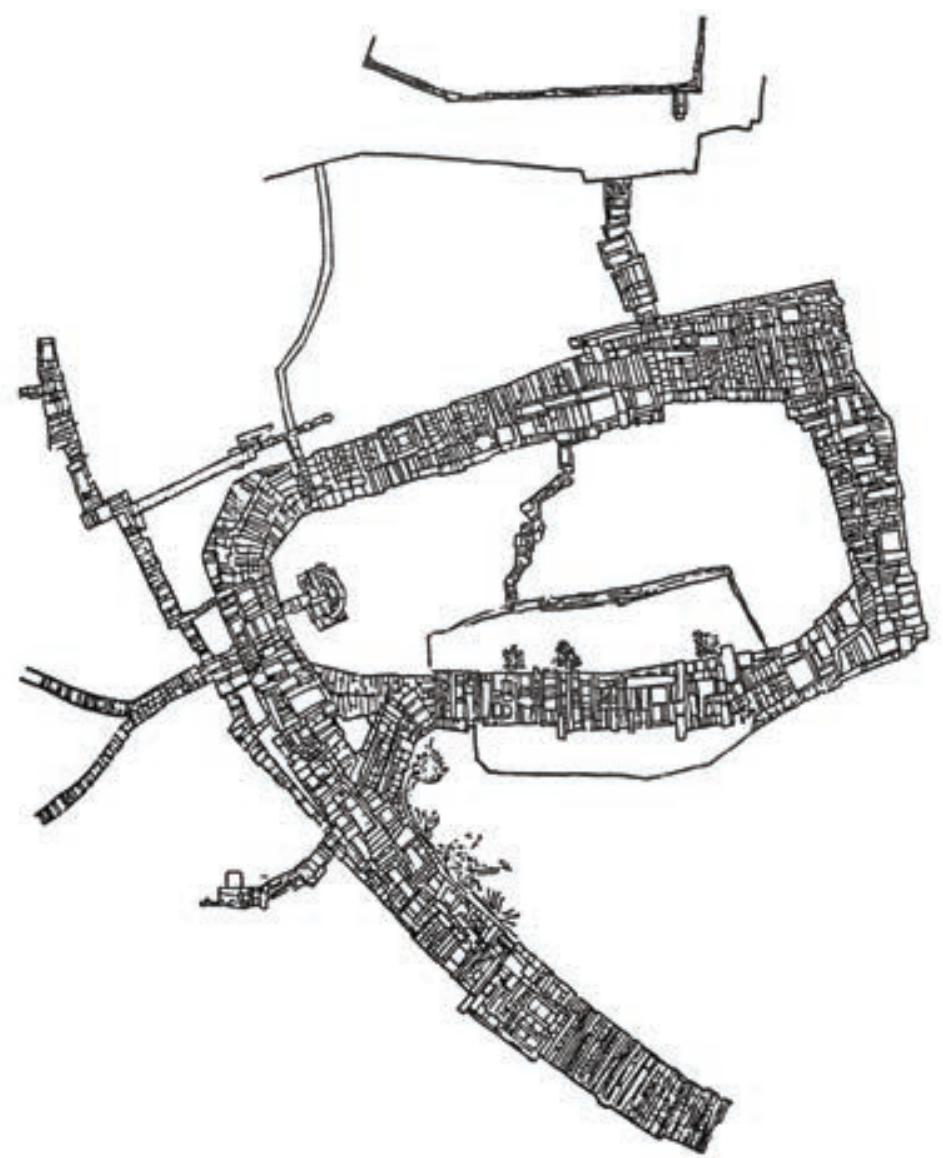

Fig. 07

Casa de la lluvia, Santander, 1979-1982. Arquitecto: Juan Navarro Baldeweg. Instalación y dibujo a lápiz sobre fondo blanco de la casa realizados por el arquitecto en 1979. (Fuente: http:// historiasdecasas.blogspot.com/2006/02/ la-casa-de-la-lluvia-santander-de-juan. html. Fecha de consulta: 26/03/2020).

Fig. 08

Piscinas das Marés, Leça de Palmeira, Matosinhos (Portugal), 1966.

Arquitecto: Álvaro Siza. (Fuente: https://commons.wikimedia.org/ wiki/File:Swimming_Pool_Piscinas_ de_Mar\%C3\%A9s_Le\%C3\%A7a_da_ Palmeira_by_\%C3\%81lvaro_Siza_foto_ Christian_G\%C3\%A4nshirt.jpg. Fecha de consulta: 13/04/2020. Fotografía: Christian Gänshirt).

Fig. 09

Dibujo en planta de la trama de caminos en piedra realizado por Dimitri Pikionis para el área arqueológica en el entorno de la Acrópolis de Atenas, 1954-1957. (Fuente: AA.VV., I Campi Flegrei. L 'Architettura per i paesaggi archeologici, Universidad degli Studi di Napoli Federico II, Dipartamento di Architettura, Nápoles, 2016, p. 266). 
seos sobre la topografía rocosa concebida por Pikionis constituye una narración sobre diferentes tiempos de la ciudad de Atenas. La intervención establece una armonía nueva con el paisaje a través de un proyecto unitario en piedra consistente en prolongar el material de desecho urbano procedente de la demolición de antiguos edificios y materiales desenterrados durante las operaciones de excavación arqueológica, hasta alcanzar la cima de la Acrópolis, fabricando un paisaje en contigüidad entre la ciudad y la colina natural de piedra ${ }^{20}$. El paseo por el lugar arqueológico es un trasbase de la materia geológica a la materia urbana y arquitectónica que cambia de forma y estado extendida irregularmente sobre la topografía. El conglomerado de elementos que componen esta red de paseos formado por la piedra natural y la piedra tallada con múltiples formas y geometrías dispuestas entre arbolado y tierra, conectan física y simbólicamente la ciudad del pasado y la ciudad actual a través de caminos con diferentes escalas y relaciones paisajísticas. La conexión entre ambas ciudades no solo es física, se prolonga también en la memoria, en un proceso de restauración territorial, piedra sobre piedra, y de transmutación de la materia en el espacio y el tiempo ${ }^{21}$. La obra y los escritos de Pikionis hablan de una suerte de "vida universal" de la materia que trasciende su propia condición física y que, como comenta Alberto Ferlenga en su escrito Signos, encuentra afinidades generales más allá de las diferentes utilizaciones y maneras de expresión de la piedra: "la combinación de experiencias distantes no es un deseo o una referencia para los arquitectos, sino parte de un mecanismo a través del cual los lugares del mundo afirman similitudes y diferencias al mismo tiempo"22.

Aunque no es posible generalizar y el repertorio de caminos en el proyecto contemporáneo es amplio, podríamos hablar de una cierta línea de pensamiento y de acción más conceptual de la arquitectura reciente, en la línea de las actuaciones de Dimitri Pikionis o de Álvaro Siza, que opera estableciendo una clara diferenciación entre los materiales de construcción y la substancia con la que se concibe la arquitectura. Estamos hablando de la transubstanciación de formas y materias herederas de una tradición cultural de los lugares y su historia, en la que el tiempo y la materia juegan un papel diferente. Si en el Movimiento Moderno construir suponía añadir, maclar, superponer , en un proceso de montaje ordenado y secuencial de materiales que finalizaba con el último acabado, ahora será la substancia primordial (pensamiento/argumento) con la que se concibe la obra, la que dará forma a la arquitectura. Las personas, la historia, los objetos y las preexistencias, junto a los materiales y la naturaleza, se convierten en las materias del proyecto arquitectónico vistos bajo una única substancia y un orden concreto de relaciones con la vida, más allá de un conjunto tipificado de sistemas constructivos.

SERENDIPIAS. EPÍLOGO
En el año 2009, en el municipio de Lanjarón situado al pie de Sierra Nevada en Granada, se llevó a cabo una actuación consistente en la recuperación de unas antiguas construcciones abandonadas junto a un río con intención de reestablecer la memoria de un pueblo y su historia con el agua ${ }^{23}$. La intervención es el resultado de una serie de implicaciones medioambientales, simbólicas, urbanísticas, arquitectónicas y sociales, tomando el agua como hilo conductor de un proyecto patrimonial en el que intervienen aspectos muy diversos de la vida del pueblo 

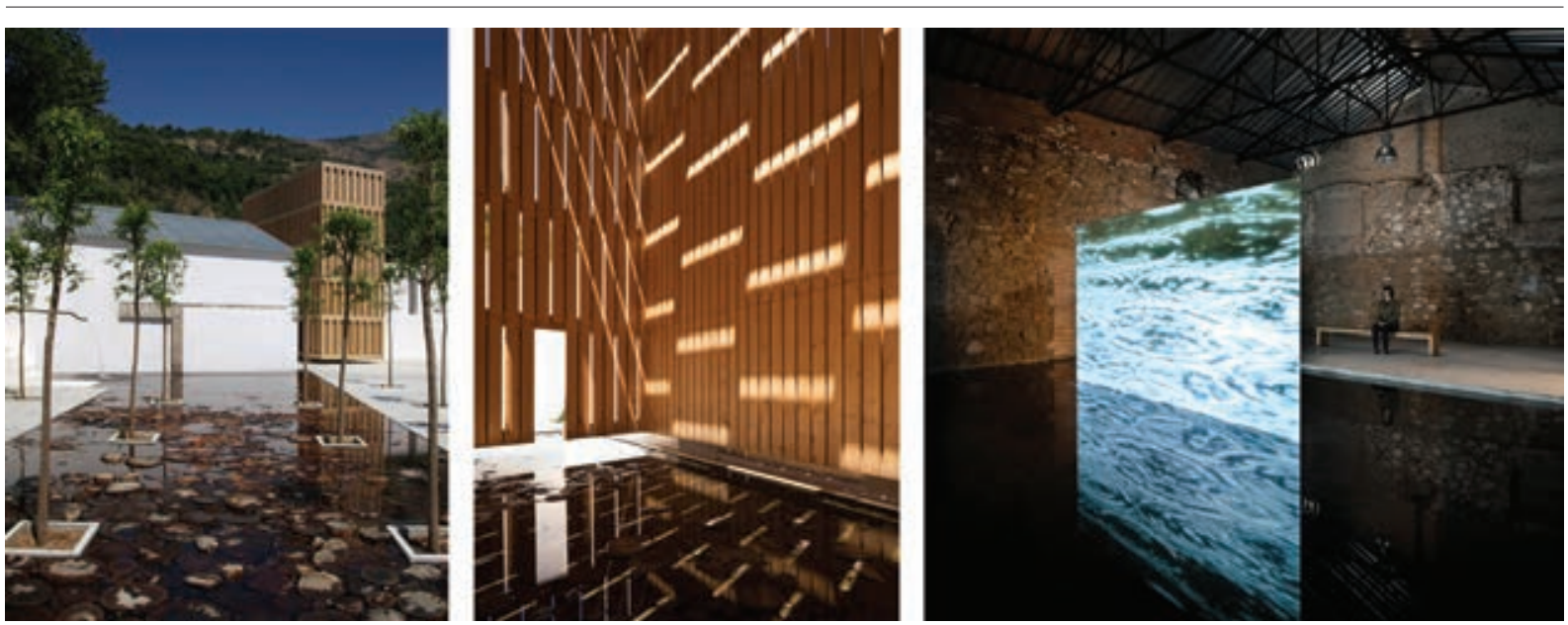

y su historia con el agua. La intervención interpela a las relaciones con este bien material a partir de una serie de contingencias con el medio, la recuperación de ciertas preexistencias, y la incorporación de acontecimientos y encuentros fortuitos acaecidos en el transcurso de las obras, infiltrándose en la historia local de sus habitantes a través de un proceso colaborativo de la ciudadanía. El agua en todo este proceso se convierte en la substancia que establece contigüidad con los diferentes "materiales" que integran la actuación en un proceso abierto a la experimentación (fig.10).

Dados los escasos medios disponibles, la intervención ha consistido en el reciclaje y reutilización de una serie de arquitecturas y otros elementos del entorno con criterios medioambientales, adaptando las antiguas naves e incorporando los trazados de agua de la acequia y el río a través de un sencillo sistema de recorridos y espacios preparados para el agua, que son inundados según el horario de riego de los campos agrícolas próximos, lo que configura un escenario de agua y arquitectura que cambia de aspecto con el transcurso del día y las labores agrícolas del entorno.

El proyecto apela a su condición narrativa para incorporar una serie de hechos y experiencias que han dado forma a la arquitectura en un proceso continuo y abierto de vivencias bajo el argumento del agua. Los elementos y las soluciones constructivas se deben a procesos participativos y a ciertos accidentes meteorológicos acaecidos durante la construcción. Los troncos de madera extendidos sobre el suelo de la plaza e inundados por el agua de la acequia de riego proceden del reciclaje de grandes eucaliptos caídos tras un vendaval que azotó durante días el parque natural de la zona, al igual que los diecisiete naranjos plantados en este espacio, que encierran la narración de una historia más amplia, diecisiete historias de otras tantas personas relacionadas con el pueblo de Lanjarón y el agua que dan cobijo y sombra a este lugar donde se rememora al agua.

El ingreso se produce ocupando el patio del antiguo matadero abandonado con un pabellón de madera que evoca la cubrición del manantial de la Capuchina, una construcción del siglo XVIII que albergaba en su interior el primer nacimiento de agua en Lanjarón, y cuyo rescate, así como los contenidos que se muestran en el interior de los espacios, es el resultado de un bando municipal del alcalde invitando a los habitantes del pueblo a abrir cajones y armarios, desempolvando restos
Fig. 10.

Museo del Agua, Lanjarón (Granada), 2009. Arquitecto: Juan Domingo Santos. Vista de la plaza de naranjos, el pabellón de ingreso y el interior del espacio inundados por el agua. (Fotografía izquierda: del autor. Fotografías centro y derecha: Fernando Alda). 
y pertenencias de sus antepasados relacionados con el agua, lo que ha permitido descubrir una fotografía inédita de este simbólico espacio, hoy desaparecido, que cubría el manantial.

Esta intervención en el paisaje, al igual que sucede con obras como Cuando la fe mueve montañas o 7000 robles. Embosquecer la ciudad frente a administrar la ciudad, está inspirada en el poder metafórico y simbólico que presentan ciertas acciones para apelar a la memoria de un pueblo y su pasado. En este caso, la vinculación al agua es el fundamento de su existencia, y muestra cómo prácticas colaborativas pueden esbozar estrategias de actuación que dan forma y cuerpo a la arquitectura, donde el agua, más que una cuestión disciplinar, está tratada como un asunto cultural con capacidad para estructurar una serie de relaciones y decisiones más amplias. El hecho de construir un espacio "entre todos" ha permitido preservar el entorno natural de la especulación urbanística y entender la intervención como la recuperación de un patrimonio paisajístico, arquitectónico y material que implica a la ciudadanía de diferente manera, desde los más jóvenes a los ancianos, que contribuyen a la divulgación de una historia viva y actual vinculada al agua. RA 
01. La obra original, de dimensiones $8 \times 11$ $\mathrm{cm}$, se encuentra expuesta en la Galería Nacional de Escocia. Véase, AA.VV., Joseph Beuys, Museo Nacional de Arte Reina Sofía, Madrid, 1994.

02. Para Beuys existe un principio global energético extendido a todas las materias del universo y a las energías mentales producidas por el individuo. En una conferencia que impartió once días antes de morir con motivo de la concesión del premio Wilhelm Lehmbruck, Beuys habló del futuro de la creación plástica como una noción energética que no solo captura lo material, lo físico, sino que se hace también extensivo a lo espiritual, a lo inmaterial.

03. El escritor Italo Calvino (1923-1985), inició al final de su vida la tarea de recoger en una serie de escritos "sus clásicos", entre los que se encontraba el ensayo sobre Ovidio y la metamorfosis bajo el título "Ovidio y la contigüidad universal". El ensayo fue editado junto a otros textos en la edición original Perché leggere i classici, Mondadori, 1991

04. CALVINO, Italo. "Ovidio y la contigüidad universal", en CALVINO, Italo, Por qué leer los clásicos, Tusquets (marginales 122), Barcelona, 1993, p.25.

05. OVIDIO NASÓN, Publio, Las

Metamorfosis (Obra completa en tres volúmenes), Editorial Gredos, Madrid, 2008.

06. Los materiales empleados por el artista son poco frecuentes en el mundo del arte, pero habituales en la vida diaria: grasa animal, cera, miel, fieltro o cobre, remiten a materias no estables susceptibles de una transformación inminente con mínima energía. La historiadora de arte y comisaria de exposiciones Kristien Stiles, en la conferencia impartida bajo el título Accesorios para la memoria. Las Aktionen de Joseph Beuys en el Macba de Barcelona en 1999, explicaba que el interés de Beuys (1921-1986) por los cambios de estado de la materia y la transubstanciación que muestran sus obras es autobiográfico y proviene de la fabulación con la que describe en su biografía cómo fue salvado de la muerte por unos nómadas tártaros tras ser abatido su avión de combate en Crimea durante la Segunda Guerra Mundial. Su cuerpo fue envuelto en grasa de animal (sebo) y fieltro (materiales empleados por el artista en su obra) hasta su curación en un proceso de conjunción de materias. Para una mayor información sobre las materias empleadas por Beuys en sus instalaciones y la degradación material y física de la propia obra del artista, véase el artículo: BARKER, Rachel y BRACKER, Alison, "Beuys is Dead: Long Live Beuys! Characterising Volition, Longevity, and Decision-Making in the Work of Joseph Beuys", en Tate Papers, Otoño 2005, n. 4.

07. Otros artistas como James Turrel o Dan Flavin trabajaron en la condición inmaterial de la luz, con instalaciones muy próximas al proyecto arquitectónico basadas en experiencias sensoriales que transforman la percepción del espacio.

\section{El proyecto se llevó a cabo en}

Ventanilla, una zona de chabolas de la periferia de Lima sometida a la dictadura de Alberto Fujimori que acababa de ser derrocada. El objetivo consistía en realizar una acción épica como respuesta a un problema social y político que había trascendido a la calle con manifestaciones de la ciudadanía. El proyecto es una metáfora sobre el potencial colectivo a través de una acción geológica realizada en el marco de la Bienal de Arte lberoamericano de Lima 2002, con la colaboración de los alumnos de la Universidad Nacional de Ingeniería de Lima. Véase información sobre este proyecto y otras actuaciones de implicación colectiva y social en el artículo de MANONELLES, Laia, "Cuando la fe mueve montañas: Utopías poéticas y políticas", en Revista de Estudios Globales y Arte Contemporáneo, 2016, número 1, pp. 205-230.

09. La acción fue realizada para la VII Documenta de Kassel de 1982 y finalizó con la plantación de la última piedra de basalto junto al roble el día de la inauguración de la VIII Documenta en 1987, cinco años más tarde. La última plantación la realizó el hijo de Beuys tras la muerte del artista el año anterior. Véase información acerca de esta obra y la implicación de la ciudadanía en, DOMINGO SANTOS, Juan, "7000 robles", en DOMINGO SANTOS, Juan, La tradición innovada. Escritos sobre regresión y modernidad, Colección Arquia/Tesis, n. 38, Fundación Arquia, Barcelona, 2013, pp. 293-307.

10. El libro es un ensayo sobre la contigüidad en los diversos campos artísticos y, en especial, sobre la arquitectura. En sus páginas se aborda la contigüidad como instrumento para superar la racionalidad constructiva amparada en la estricta lógica funcional que se produce desde la consideración del material, nunca desde la experiencia o la relación con otras cuestiones fuera de la disciplina arquitectónica. TRILLO DE LEYVA, Juan Luis, Argumentos, sobre la contigüidad en la arquitectura, Universidad de Sevilla, Sevilla, 2001.

11. AA.VV., El Manifiesto de la Alhambra, Revista Nacional de Arquitectura, Madrid, 1953.

12. AA.VV., El Manifiesto de la Alhambra 50 años después. El Monumento y la Arquitectura Contemporánea. Colección Monografías de la Alhambra, n.1, Patronato de la Alhambra y Generalife y TF Editores, Madrid, 2006.

13. JUEZ JUARROS, Francisco, Símbolos de poder en la arquitectura de Al-Ándalus, Universidad Complutense de Madrid, Facultad de Geografía e Historia, Madrid, 1999 (Tesis doctoral).

14. Como sucede en arquitecturas icónicas significativas de la modernidad, entre ellas, el pabellón para la Feria de Barcelona (1929) de Mies van der Rohe y la Casa de la Cascada (1935) de Frank Lloyd Wright, donde el agua forma parte de un escenario de fondo de la arquitectura, o en las intervenciones de Luis Barragán en la zona paisajística de las Arboledas (1961) y en algunos de sus espacios domésticos (La Casa Gálvez, 1954, y la Casa Gilardi, 1976). En ellas, la conjunción de la luz con el agua, dotan de efectos de teatralidad al paisaje y al interior de los espacios que cambian de aspecto con las sombras de las estaciones a lo largo del año, al igual que sucede en los dos proyectos de capillas realizados por Tadao Ando, la Iglesia sobre el Agua (1988) y el Templo del Agua (1991), convertidos en experiencias sensoriales en una conexión espiritual de la arquitectura con la naturaleza.

15. DE BALZAC, Honoré, La búsqueda del Absoluto, Nórdica Libros, Madrid, 2018.

16. AA.VV. Scarpa: Carlo. La Fondazione Querini Stampalia a Venezia, Electa, Firenze, 2006. 
17. La idea de una casa "bañada" por el agua de lluvia se encontraba ya presente en una instalación realizada por el autor en el año en el que empezó el diseño de la casa. La instalación es una obra conceptual consistente en una pequeña maqueta de una casa con cubierta a dos aguas en cobre, y un serpentín que continuamente deja resbalar el agua de la cubierta por los muros, inundando todas las superficies de la casa, el suelo y su entorno. El resultado es una particular visión de un objeto mojado por la fina lluvia artificial que enlaza en continuidad la forma de canalizar el agua, las paredes por la que resbala y la superficie horizontal del suelo sobre el que se asienta.

18. CURTIS, William, "Álvaro Siza: una arquitectura de bordes", en revista $E I$ Croquis, 1994, n. 68-69 "Álvaro Siza 19581994", pp. 32-45.

19. COHEN, Jean Louis, "Una arquitectura sin mayúsculas", en AV Monografías, 2016, n. 186-187 “Álvaro Siza 1995-2016”, p. 10.

20. Véase ÁLVAREZ ÁLVAREZ, Darío, "El paisaje como obra de arte total. Dimitri Pikionis y el entorno de la Acrópolis", en revista $R A$ 2011, n. 13, pp. 37-50. Más información de interés puede encontrarse en, DI PALMA, Bruna, "Ri (n) tracciare relazioni. Strategie progettuali per le rovine archeologiche monumentali di pozzuoli", y ASCOLESSE, Marianna, "La strada del bene comune. Il segno del passato nel presente", en AA.VV. I Campi Flegrei. L'Architettura per i paesaggi archeologici, Universidad degli Studi di Napoli Federico II, Dipartamento di Architettura, Nápoles, 2016.

21. En 1936, el escritor Níkos Kazantzáki escribió El jardín de las rocas en la isla griega de Egina donde solía pasar las vacaciones estivales al igual que su amigo Pikionis. El libro recoge las experiencias del viaje del escritor a Japón y China con descripciones de la cultura oriental y su relación con la naturaleza. Es probable que el libro influyera en la obra arquitectónica de Pikionis y la manera de entender el uso de la piedra con una dimensión más amplia que la exclusivamente técnica.

22. FERLENGA, Alberto, "Signe", en AA. VV. Paesaggi di rovine. Paesaggi rovinati, Sapienza Universitá di Roma, Roma, 2014, p. 298.
23. La obra fue realizada por el arquitecto Juan Domingo Santos con la colaboración de miembros de su estudio, el jardinero municipal, el alcalde y los habitantes del municipio de Lanjarón, dentro de una serie de actuaciones encaminadas a la recuperación paisajística de la margen del río Lanjarón que desciende de Sierra Nevada. La obra, denominada Museo del Agua, se inició con la búsqueda de un lugar en el que se favoreciera la presencia del agua en unas condiciones naturales. 


\section{Referencias Bibliográficas}

\begin{abstract}
- ÁLVAREZ ÁLVAREZ, Darío, “El paisaje como obra de arte total. Dimitri Pikionis y el entorno de la Acrópolis", en revista RA 2011, n. 13.
\end{abstract}

- ASCOLESSE, Marianna, "La strada del bene comune. Il segno del passato nel presente", en AA.VV. I Campi Flegrei. $L$ 'Architettura per i paesaggi archeologici, Universidad degli Studi di Napoli Federico II, Dipartamento di Architettura, Nápoles, 2016.

- AA.VV., El Manifiesto de la Alhambra, Revista nacional de Arquitectura, Madrid, 1953.

-AA.VV., El Manifiesto de la Alhambra 50 años después. El Monumento y la Arquitectura Contemporánea. Colección Monografías de la Alhambra, n. 1, Patronato de la Alhambra y Generalife y TF Editores, Madrid, 2006.

-AA.VV., Joseph Beuys, Museo Nacional de Arte Reina Sofía, Madrid, 1994.

-AA.VV. Scarpa: Carlo. La Fondazione Querini Stampalia a Venezia, Electa, Firenze, 2006.

- BARKER, Rachel y BRACKER, Alison, "Beuys is Dead: Long Live Beuys! Characterising Volition, Longevity, and Decision-Making in the Work of Joseph Beuys", en Tate Papers, Otoño 2005, n. 4. (https://www.tate.org.uk/research/ publications/tate-papers/04/beuys-isdead-long-live-beuys-characterisingvolition-longevity-and-decision-makingin-the-work-of-joseph-beuys. Fecha de consulta, 20 de marzo 2020).

- CALVINO, Italo, Por qué leer los clásicos, Tusquets (marginales 122), Barcelona, 1993.

- COHEN, Jean Louis, "Una arquitectura sin mayúsculas", en AV Monografías, 2016, nn. 186-187 “Álvaro Siza 1995-2016”, p. 10.

- CURTIS, William, "Álvaro Siza: una arquitectura de bordes", en revista $E I$ Croquis, 1994, n. 69-69 "Álvaro Siza 19581994", pp. 32 a 45.

- DE BALZAC, Honoré, La búsqueda del Absoluto, Nórdica Libros, Madrid, 2018.
- DI PALMA, Bruna, “Ri (n) tracciare relazioni. Strategie progettuali per le rovine archeologiche monumentali di pozzuoli", en AA.VV. I Campi Flegrei. L 'Architettura per i paesaggi archeologici, Universidad degli Studi di Napoli Federico II, Dipartamento di Architettura, Nápoles, 2016.

- DOMINGO SANTOS, Juan, La tradición innovada. Escritos sobre regresión y modernidad, Colección Arquia/Tesis, n. 38, Fundación Arquia, Barcelona, 2013.

- FERLENGA, Alberto, "Signe", en AA. VV. Paesaggi di rovine. Paesaggi rovinati, Sapienza Universitá di Roma, Roma, 2014.

- JUEZ JUARROS, Francisco, Símbolos de poder en la arquitectura de Al-Ándalus, Universidad Complutense de Madrid, Facultad de Geografía e Historia, Madrid, 1999 (Tesis doctoral).

- MATTEINI, Tessa, Paesaggi del tempo. Documenti archeologicie rovine artificiali nel disegno del paisaggio, Universidad degli studi Firenze, Florencia, 2009.

- MANONELLES, Laia, "Cuando la fe mueve montañas: Utopías poéticas y políticas", en Revista de Estudios Globales y Arte Contemporáneo, 2016, número 1, pp. 205230.

- OVIDIO NASÓN, Publio, Las Metamorfosis (Obra completa en tres volúmenes), Editorial Gredos, Madrid, 2008.

- TRILLO DE LEYVA, Juan Luis, Argumentos, sobre la contigüidad en la arquitectura, Universidad de Sevilla, Sevilla, 2001.
RA. Revista de Arquitectura Núm. 22 - 2020 P. 96-111 